\title{
USE OF GROUP SUPPORT SYSTEMS IN TODAY'S SOCIETY
}

\author{
Roger L. Hayen, Central Michigan University, roger.hayen@cmich.edu \\ Stephanie A. Swaby, Central Michigan University, swaby1sa@cmich.edu \\ Zhenyu Huang, Central Michigan University, huang1z@cmich.edu
}

\begin{abstract}
Group support systems are increasingly being used in business, academic, and other organizations. Group support systems are collaborative software tools that can be used to focus and structure a team's deliberation, while minimizing costs and distractions among teams working collaboratively. Several advantages are present such as anonymity, parallel communication, automated record keeping, more structure, and increased productivity. Companies such as IBM, Procter and Gamble, Boeing and Marriott have used these systems to reduce meetings times and project times by 90 percent. Overall, e-collaboration is changing the landscape of communication.
\end{abstract}

Keywords: Group support systems, groupware

\section{INTRODUCTION}

Today's business challenges focus on reducing and controlling costs, competing globally, improving quality, improving customer service and accelerating the product development cycle [3]. Decision making with groups is an important process within companies and strongly supported in universities. Policies, budget plans, and other organizational tasks frequently involve group discussions or meetings. Collaboration within groups can be very effective as knowledge is increased, but being geographically dispersed can present a problem. Group support systems (GSS) can be defined as an information technology-based environment using computer-mediated communications to support the work of groups that maybe geographically dispersed [10]. GSS software offers organizations a range of applications from brainstorming to categorizing to analyzing alternatives [16]. These systems allow people to share, organize, evaluate, make decisions, and plan for action [19].

Companies use GSS to reduce travel expenses, increase effectiveness of group decision making, increase communication and collaboration and increase creativity [6]. A survey was conducted concerning the usefulness of group support systems with 441 users at IBM and Nationale-Nederlanden, a large insurance firm. Both companies rated group support systems as being highly useful, and it saves time [1] There are a number of GSS products on the market such as Netscape's Collabra Share, Novell's Groupwise, Microsoft's Exchange and Group Systems products [17]. Although there are many advantages, a major concern with utilizing GSS is the elimination, of traditional face-to-face (FTF) communication. Since FTF communication is eliminated those who use GSS need to be aware of this and then still find ways to effectively communicate among their group members.

The purpose of this research effort is to examine the use of GSS within society and the business world. The layout of the paper is as follows; first an introduction, followed by a literature review, and then a discussion which includes types of GSS, their advantages/disadvantages, the enabling technology, and factors of computer mediated communication that affect performance are presented. Finally a conclusion to the study is given.

\section{LITERATURE REVIEW}

Group decision-making is an important and frequently encountered process within companies and organizations both in the public and private sector [11]. When GSS tools are used for the purpose of this decision making, they are best known as group decision support systems (GDSS). GDSS tools include features that support group work in formulating alternative business decision and then conducting the group processes to evaluated, rank, and select an alternative, that is to make group decisions. These GDSS are designed to support the decision-making processes through analysis of alternatives, negotiating and voting. Group members communicate by exchanging written messages rather than interacting verbally [15]. GSS that support group communication, in general, are used to increase the effectiveness and efficiency of group interaction by facilitating the interactive sharing of information among group members [10]. Hence a GSS is a suite of collaborative software tools that can be used to focus and structure a team's deliberation, while reducing cognitive costs of communication and information access [1]. It also reduces distraction among teams working collaboratively towards a goal [1]. So, in addition to facilitating collaboration, GDSS software is used in organizations for brainstorming and categorizing complex means of analyzing alternatives [16]. Thus, 
the formulating, ranking, and voting to make a decision encompass the key features that distinguish a GDSS from a GSS.

Overall, GSS offer an added value for collaborative problem solving by providing support for parallel communication, anonymous interaction and automatic recording of meeting minutes [18]. Communication in GSS frequently can be conducted with anonymity. Anonymity in GSS and GDSS is defined as the inability of group members to identify the origin of messages they receive and the destination of messages they send [15]. Anonymity allows ideas to be exchanged, which promotes increased participation by group members and allows more information to be shared [2]. Anonymity has the ability to stimulate interaction because group members feel less threatened with expressing their ideas, and it reduces inhibition. Anonymity appears to be more important in a GDSS setting than a GSS environment [15].

Brainstorming electronically using GDSS tools is considered a better technique than verbal brainstorming, or nominal group because it combines the advantages of working alone; therefore reducing blocks [15]. Nominal groups are found to be more productive in quality and quantity then interactive groups and they presented advantages over FTF groups in terms of the number, quality and originality of generated ideas [15].

Academic and business organizations worldwide are using GSS and GDSS. Procter and Gamble, J.P. Morgan, Westinghouse, Texaco and Greyhound have purchased systems for use and IBM, Boeing and Marriott have used the systems to reduce meeting times and total project times by 90 percent [2].

\section{TYPES OF GROUP DECISION SUPPORT SYSTEMS}

There are four types of GDSS settings which are a decision room, local area decision network, legislative session and computer-mediated conference. A decision room holds a small group ranging from three to twenty-four people in a FTF meeting. A local area decision network is used when a small group of members are unable to meet FTF and are dispersed in a limited geographical area and a legislative session is used when a group of fifty to one hundred people, is too large to meet in a decision room [2]. With a local area decision network, group members can meet asynchronously using a computerized bulletin board or synchronously using a realtime document editor [2]. A computer-mediated conference is used for a large group dispersed geo- graphically. Computer, audio and video conferencing allow geographically dispersed group members to communicate [2]. With this type of meeting members send their input to a central database or electronic mailbox and other participants can respond to the input and eventually a decision is made by consensus [2]. Figure 1 shows the different categories of GSS based on a time/space framework. The time component shows when interactions between group members occur and the place component describes the location of the group members during interactions. The web-based GSS tend to focus on collaborative communication using information technology, in general, and the Internet, more specifically. This GSS can be categorized as computer-mediated communication or e-collaboration. On the other hand, the same-time and same-place GSS are usually centered more on support for brainstorming and decision making, which are primarily GDSS functions. As Figure 1 illustrates, many of the features for collaboration and decision making overlap in the time/place framework. However, it is readily apparent that some of those functional features are more oriented specifically to decision making activities, while others have a focus on e-collaboration or sharing. That is, just communicating to get a task accomplished most effectively. The ranking and voting features are more supportive of the GDSS decision making, whereas the sharing capabilities are the groupware for e-collaboration.

The matrix shows different types of systems or capabilities that are needed based on the location and time. The matrix is useful for companies interested in incorporating GSS or GDSS tools in their organization. There does not appear to be a single tool that does it all. Hence, the group support needs should be matched to the requirements for group interactions and sharing.

\section{ADVANTAGES AND DISADVANTAGES OF GROUP SUPPORT SYSTEMS}

GSS are becoming increasingly popular due to the systems ability to enhance group productivity and interaction. GSS offer a feasible and attractive alternative to the traditional FTF meeting environments and managers find them more useful, because meetings can often waste time or are unproductive [2]. However, although there are several advantages over verbal FTF meetings, there are some disadvantages are well. Figure 2 lists the advantages and disadvantages to GSS. 


\section{Time/Place Framework}

\begin{tabular}{|c|c|c|}
\hline $\begin{array}{l}\text { Same } \\
\text { Place }\end{array}$ & $\begin{array}{l}\quad \text { Same Time } \\
\text { - GSS in a decision room } \\
\text { - Web-based GSS } \\
\text { - Multimedia presentation } \\
\text { - Whiteboard } \\
\text { - Document sharing }\end{array}$ & $\begin{array}{l}\quad \text { Different Time } \\
\text { - GSS in a decision room } \\
\text { - Web-based GSS } \\
\text { - Workflow management } \\
\text { - Document sharing } \\
\text { - E-mail, V-mail }\end{array}$ \\
\hline $\begin{array}{l}\text { Different } \\
\text { Place }\end{array}$ & $\begin{array}{l}\text { - Web-based GSS } \\
\text { - Multimedia presentation } \\
\text { - Whiteboard } \\
\text { - Document sharing } \\
\text { - Video Conferencing } \\
\text { - Audio conferencing } \\
\text { - Eomputer conferencing } \\
\text { - E-mail, V-mail }\end{array}$ & $\begin{array}{l}\text { - Web-based GSS } \\
\text { - E-mail, V-mail } \\
\text { - Whiteboard } \\
\text { - Workflow management } \\
\text { - Document sharing } \\
\text { - Computer conferencing with } \\
\text { memory }\end{array}$ \\
\hline
\end{tabular}

Figure 1: Time-place framework

Source: Group support systems: technologies and products selection [6]

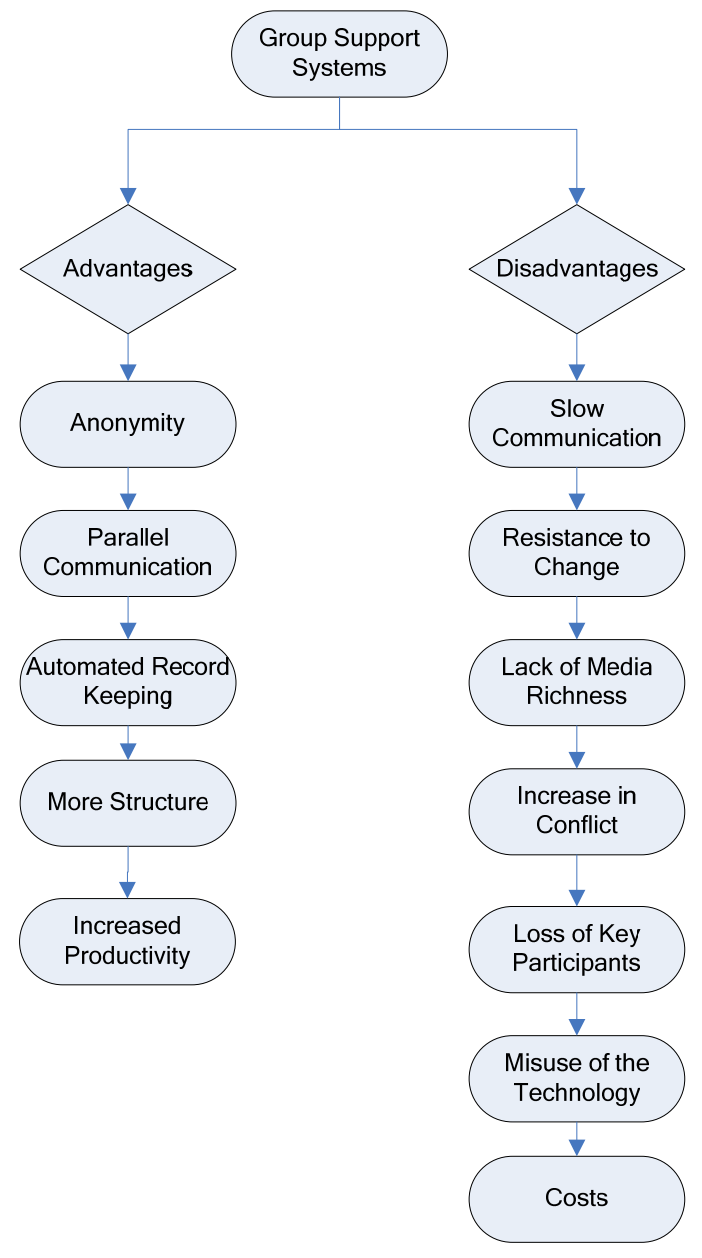

Figure 2: Advantages and Disadvantages of Group Support Systems

\section{Advantages}

There are many advantages to GSS. Advantages include anonymity, parallel communication, automated record keeping, more structure and increased productivity. Anonymity allows ideas to be exchanged which promotes increased participation by group members and allows more information to be shared [2]. Group members therefore do no feel fear of ridicule from other group members and participants feel less compelled to conform to the group's or boss's opinion. One researcher found that over 85 percent of tasks that involved anonymity were about idea generation and it encourages the participation of the group members in the presentation of non-conventional or less common ideas [15].

In FTF meetings, people must listen to others speak and cannot pause to think, but a GDSS allows everyone to speak in parallel. In traditional meetings each person has only a few minutes to express ideas. GSS allows communication throughout the entire meeting. Increased participation and group synergy is present. Group synergy occurs because group members are able to use an idea in a manner that the originator did not anticipate, and because participants have different levels of information skills [2].

A GDSS may automatically records comments, votes rankings, and other information shared by a group onto an electronic file, therefore there is automated record keeping [2]. This allows notes to no longer be taken manually or for participants to mentally keep track of what was said. In traditional group settings participants often fail to comprehend what was said 
or may be unable to process the information quickly enough to participate effectively [2].

Also more structure and focus is brought to a meeting making it more difficult to deviate from the problemsolving cycle and make incomplete or premature decisions. Greater productivity is also achieved since total meeting time is reduced and an increase in better decisions. IBM has reduced meeting times by over $50 \%$ and Boeing has reduced overall project times by over $90 \%$ [2].

\section{Disadvantages}

Although there are several advantages to group support systems there are several disadvantages as well. Disadvantages include slow communication, resistance to change, lack of media richness, increase in conflict, loss of key participants, misuse of technology and costs.

People have different learning styles and some pick up concepts or techniques at a slower pace than others. Most people do keyboard entry at a much slower rate than they can communicate verbally. Some participants are keyboard challenged and have very minimal keyboarding skills, although this appears to be a diminishing impediment. It is generally more efficient to use a GDSS only for a larger group. When group size is greater than eight, the advantage of parallel communication tends to outweigh the disadvantage of limited keyboarding skills.

Humans are often very resistant to change especially with technology. People are often intimidated by computers and feel threatened when meeting new people. Using a GSS involves training to use the software and people may be resistant to learn how to use the system. High-level executives who are not computer literate are more likely to have a bias against using the technology in favor of the more traditional meeting [2].

GDSS rely on written information, and therefore other forms of communication are minimized. In traditional meetings, body language and facial expressions can help group members determine the context and connotation of a comment. Group members prefer FTF communication and GSS can make meetings impersonal and completely issue-oriented. Also there could be an increase in conflict due to anonymity in the meeting, because some people may be critical in their comments. Participants may misuse the technology because the comments are anonymous and one participant could submit multiple comments stimulating multiple participants. This would make it seem that more people agree with a comment when they may be false. Also people who prefer to dominate a verbal meeting may be less interested in participating with group support systems because they are unable to use their string verbal skills [2]. However, shy participants are more likely to participate, and this increases their contributions.

One major concern with GSS and GDSS software tools is the cost which has ranged from $\$ 15,000$ to over $\$ 50,000$. This is especially the situation with GDSS that is designed for use in a decision room setting. Therefore, a considerable monetary commitment may be involved and may not be cost efficient unless it gains acceptance and is used regularly and properly within a business. Specially designed GDSS meetings rooms at the University of Arizona and the University of Mississippi have a cost of $\$ 250,000$. Smaller-scale meeting rooms may cost at least \$90,000 [2]. However, more recent developments and enhancement in publicly available and web-based e-collaboration has made many GSS features accessible at little or no cost to all Internet users.

\section{GROUP SUPPORT SYSTEM TECHNOLOGIES}

Undoubtedly, GSS system have become popular in corporations that want to reduce travel costs, increase the effectiveness of group decision-making and foster an environment that brings out ideas or creativity [6]. Companies look for GSS that are affordable, flexible and integrate with their existing information technology environment [6].

There are several collaborative tools on the market such as WebDemo, Sametime, eRoom, Microsoft NetMeeting, Interwise, Groove, PlaceWare, WebEx and GroupSystems. Each software tool offers many features and benefits that may be useful to an organization depending on their needs. The e-collaboration functionality of GSS is available to any average Internet user through groups, such as those from Google [8], MSN [14], and Yahoo [20]. Below some benefits of GroupSystems, NetMeeting, Groove, Google Groups, and Blackboard are discussed.

GroupSystems software incorporates brainstorming functionality and is especially valuable in situations where anonymity, ranking, and voting are needed. It allows all participants to think and contribute outside the normal FTF meeting boundaries and allows all individuals to engage in creative or problem solving objectives rather than only a few [9]. GroupSystems online meeting tools provide structure and include the added value of anonymity, when required. Organizations using GDSS software are experienced cost savings of 50 to 75 percent of the cost and time associated with traditional FTF meetings [9]. Clearly 
GroupSystems software has a very robust feature set that facilitates many GDSS functions that are not present in some of the other GSS tools.

Microsoft's NetMeeting offers videoconferencing, remote desktop sharing, and added security. Data encryption, user authentication and password protection are available to ensure security [13]. Audio and video enhancements allow group members see other people and share ideas and conversations. The whiteboard feature allows participants to collaborate in real time with others using graphic information and the remote desktop sharing option lets users call a remote computer to access its shared desktop and applications [13].

Another GSS software is Microsoft's Groove. Groove helps to manage meetings and projects and track data and processes [12]. Relevant information such as data, files, messages, meetings, and forms are brought together in one place for everyone in the team to view. Team members within the organization and outside the organization can be brought together and group members can always know the virtual location, or online presence of other group members which allow for quick conversation and collaboration [12]. Also everyone can work with the same information whether they are online, offline or on a low bandwidth connection.

Google's Groups [8] and Docs \& Spreadsheets [7] facilitate GSS e-collaboration for the average Internet user, because this group support is provided at no cost. With Groups, a discussion board or group is established for sharing ideas. Users post and reply to information posted within a group. A group may be open or closed. Anyone can participate in an open group, whereas, only invited individuals can enter a closed group. Many different groups exist on various categories. With Docs \& Spreadsheets, users have a shared work area for their e-collaboration. They can post document or spreadsheet files for others to view and change. Changes can be made by users working together at the same time. That is, the documents are shared in real-time. This e-collaboration is carried out using a web browser. Hence, this is an any place GSS tool.

Blackboard [5] is a course management tool or an elearning tool that supports the delivery of educational coursework. Although specifically designed to support educational courses, it contains several GSS features that are worthy of consideration. Clearly, Blackboard is not a DSS tool. The point is that it does, however, contain similar e-collaboration features. Discussion boards provide for posting and otherwise sharing ideas. Posts may include attachments. Usually, the contents of discussion groups are limited to the students enrolled in the course. Other communication support within Blackboard is specifically a Group category. This allows sub-groups of students within a course to have their own space for exchanging ideas and other information. Group members are usually established by the course instructor who has administrative responsibility for the course within Blackboard.

These examples of GSS portray a wide range of functional features. Many of those feature overlap among these products. Other features are more limited in their inclusion in GSS tools. Nonetheless, this variety of GSS tools illustrates the diversity of GSS capabilities for today's businesses and society.

\section{DISCUSSION}

There are a number of factors of computer mediated communication that affect organizational performance from group or team endeavors, especially those of e-collaboration. The principal objective of GSS is to increase the effectiveness and efficiency of group interaction by facilitating the interactive sharing of information among group members. However, computer-mediated communication lacks social presences and affects the perception and interpretation of the meaning of messages exchanged which makes the exchange of information among dispersed groups member difficult [10]. Due to the low immediacy of communication and lack of sufficient socio-emotional cues present in computer-mediated communication compared to FTF meetings, decision time is extended and there is failure to reach consensus within the allotted time [4]. The inability of computer-mediated communication to convey socioemotional content in messages is found to engender lower satisfaction with the problem-solving process [4].

Leadership in groups can clarify the path to the group's goal, reducing obstacles that prevent the group from reaching these goals and increase the group's satisfaction toward achieving the goal [10]. Leaders can establish and maintain the link between satisfaction and group performance by employing different leadership styles whose effectiveness can be moderated by the nature of the task [10]. The leader must be able to adapt to different agendas and activities and examine issues from different perspectives and at the same time have a command of the technology [16]. However, interactive groups may tend to perform poorer because the members tend to adjust their productivity to the least productive member of the group [15]. The presence of a leader alone does not make a difference; the leader has to perform properly to their leadership role [10]. A study by 
Kim [10] found that groups with a leader reported a higher level of satisfaction with the decision process than groups without a leader and parallel communication mode groups reported a higher level of satisfaction with the decision process than sequential communication groups. This potential disadvantage is addressed by even the lowest level, no cost e-collaboration tools where a group leader sets up the group space and invites group participants.

Some of the groupware tools have a specific focus on decision making activities. These GDSS, such a GroupSystems, include functional features to support the processes necessary to reach a shared group decision concerning a business problem or opportunity. Other groupware are directed towards sharing information. These GSS, such as Google Groups, support environments for e-collaboration with discussion groups and document sharing, but without features such as ranking and voting on alternatives.

The group communication environment is changing rapidly with the emergence of new technologies, where many of the e-collaboration tools are now available at little or no cost. This increase in technology allows group participants to see each other and show emotions when using video conferencing, audio and text chats. These participants are able to receive some of the same benefits that groups receive when they engage in FTF meetings.

The bottom line is this. Many groupware tools are now available with a wide variety of functional features and costs. Business teams and individuals need to examine their requirements and match them with the capabilities and costs of GSS alternatives. These alternatives now include group support for the average Internet user and can be applied to more personal uses such as family photo albums and genealogy studies. On the other hand, businesses now have a wide variety of options for supporting team efforts with computer mediated tools for more effective group processes and interactions.

\section{CONCLUSION}

GSS are extremely advantageous to business organizations, academic organizations, and individuals. They are gaining acceptance as an effective computer-based communication tool. Teamwork and decisions made by groups are an important process within companies and are encouraged in academic settings. Groups geographically dispersed can communication as if they were together in one location at the same time. The organizations that currently use these systems are reducing travel costs while increasing productivity. New technologies and improved features will attract organizations that cur- rently don't use group support systems so they can recognize the benefits of this collaborative tool. Since organizations compete globally, GSS facilitate communication process both with those inside and outside the organization. This is a flourishing use of GSS.

The academic environment frequently has students participate in group or team projects and related interactions. Options are available to meet these collaboration efforts. They may be conducted via e-mail, within a course management system, or with other widely available, low cost tools. Which is best depends on the collaboration that best support course delivery. So, academicians are now faced with many of the same alternatives in selecting that combination of features which best provides collaboration for a particular learning environment. Based on the trend of a continually expanding GSS tool sets examined in this research, the barriers to e-collaboration have been removed by enhancements in the technology. The real challenge now is how to best use these technologies.

Clearly, GSS that provide e-collaboration have become mainstream in the past decade. No longer is this technology only for major corporations. It is readily available and widely used by the average Internet connected private individual. However, this has also fueled the growth of GSS e-collaboration throughout corporations and today's society. The message is crystal clear. If you are not using GSS with any team or group related activities in work, academic, or personal endeavors, then you should ask yourself why you are not using this technology. The technology is not the limiting factor, but rather it is your collaboration processes that need to be reexamined.

\section{REFERENCES}

1. Agres, A.B., Vreede, G., Briggs, R.O. (2005). A Tale of Two Cities: Case Studies of Group Support Systems Transition. Group Decision and Negotiation, 14(4), 267- 286.

2. Aiken, M., Vanjani, M., Krosp, J. (1995). Group decision support systems. Review of Business, 16(3), 38-43.

3. Akkirman, A.D., Harris, D.L. (2005). Organizational communication satisfaction in the virtual workplace. The Journal of Management Development, 24(5), 397-410.

4. Andres, H.P. (2002). A comparison of face-toface and virtual software development teams. Team Performance Management, 8(1), 39-49.

5. Blackboard (2007). Academic Suite. Retrieved April 14, 2007 from 
http://www.blackboard.com/clientcollateral/Aca demic_Suite_Brochure_new.pdf.

6. Bose, R. (2003). Group Support Systems: Technologies and products selection. Industrial Management + Data Systems, 103(8), 649-657.

7. Google (2007). Google Docs \& Spreadsheets. Retrieved April 17, 2007 from http://www.google.com/google-d-s/b1.html.

8. Google (2007). Google Groups. Retrieved April 19, 2007 from http://groups.google.com.

9. GroupSystems (2006). GroupSystems : The World Leader in Group Intelligence and Decision-Making Technology. Retrieved November 21, 2006 from http://www.groupsystems.com.

10. Kim, Y. (2006). Supporting Distributed Groups with Group Support Systems: A Study of the Effect of Group Leaders and Communication Modes on Group Performance1. Journal of Organizational and End User Computing, 18(2), 20-38.

11. Matsatsinis, N.F., Grigoroudis, E., Samaras, A. (2005). Aggregation and Disaggregation of Prefereneces for Collective Decision-Making. Group Decision and Negotiation, 14, 217-232.

12. Microsoft (2006). Grove Virtual Office. Retrieved November 20, 2006 from http://www.groove.net/home/index.cfm

13. Microsoft (2006). NetMeeting Features. Retrieved November 21, 2006 from http://www.microsoft.com/windows/NetMeeting /Features/default.ASP.

14. MSN (2007). MSN Groups - More Useful Everyday. Retrieved April 21, 2007 from http:/groups.msn.com.

15. Pissarra, J. and Jesuino, J.C. (2005). Idea generation through computer-mediated communication: The effects of anonymity. Journal of Managerial Psychology, 20(3), 275-292.

16. Ready, K.J, Hostager, T.J., Lester, S., Bergmann, M. (2004). Beyond the Silo Approach: Using Group Support Systems in Organizational Behavior Classes to Facilitate Student Understanding of Individual and Group Behavior in Electronic Meetings. Journal of Management Education, 28(6), 770-790.

17. Siau, K. (2004). Evaluating the Usability of a Group Support System using Co-Discovery. Journal of Computer Information Systems, 44(2), 17-29.

18. Vreede, G., Brujin, H. (1999). Exploring the boundaries of successful GSS application: Supporting inter-organizational policy networks. Database for Advances in Information Systems, 30(3), 111-131.

19. Vreede, G., Davison, R.M., Briggs, R.O. (2003). How a silver bullet may lose its shine. Associa- tion for Computing Machinery. Communications of the ACM, 46(8), 96-103.

20. Yahoo (2007). Yahoo! Groups. Retrieved April 17, 2007 from http://groups.yahoo.com. 